\title{
Idea work online: shelters and crutches in remote collaborative autoethnography
}

Anna Dziuba and Janne Tienari

Management and Organisation, Hanken School of Economics, Helsinki, Finland, and Liisa Välikangas

Technology, Management and Economics Innovation, Technical University of Denmark, Lyngby, Denmark

Received 26 January 2021 Revised 14 June 2021 29 June 2021

Accepted 29 June 2021

\begin{abstract}
Purpose - The three authors of this paper are intrigued by ideas and how they are created. The purpose of this paper is to explore idea creation and work by means of remote collaborative autoethnography.

Design/methodology/approach - During the COVID-19 lockdown in 2020, the authors sent texts to each other, followed up on each other's thoughts and discussed them in online meetings. They shared, analyzed and eventually theorized their lived experiences in order to understand creating ideas as social and cultural experience.

Findings - The authors develop the notions of "shelter" and "crutch" to make sense of the complexity of creating ideas together; theorize how emotions and identities are entangled in idea work; and discuss how time, space and power relations condition it.

Originality/value - The authors contribute to understanding idea work in a remote collaborative autoethnography by highlighting its emotional, identity-related and power-laden nature.
\end{abstract}

Keywords Emotion, Identity, Power relations, Collaborative autoethnography, Idea work

Paper type Research paper

\section{Introduction}

Not sure why etiology, or aetiology, makes me excited, but then I love concepts. And why not? Etiology is the classic, as in Greece, study of causation, and what could be more wonderful than understanding how things become what they are? Of course, not everything is causation, there is also emergence, serendipity, randomness.

When I think about etiology, I like the idea of mapping something out, because I like to make thoughts visual, organize them. It helps me to make sense of them, find answers, assumptions, things that are not obvious and be surprised.

I have no idea what etiology is or means, or why it should be fruitful for making sense of things that are essentially social. I dislike concepts and metaphors from natural sciences and medicine, and I have problems with causation, but you managed to arouse my curiosity.

These are examples from our early exchange of thoughts on idea creation. During the COVID-19 lockdown in the spring and summer of 2020, we - a doctoral researcher and two professors - sent texts to each other, taking turns, and followed up on each other's thoughts. We engaged in collaborative autoethnography (Geist-Martin et al., 2010; Chang et al., 2012; Kiriakos and Tienari, 2018; Nordbäck et al., 2021) and sought to describe and analyze our

(C) Anna Dziuba, Janne Tienari and Liisa Välikangas. Published by Emerald Publishing Limited. This article is published under the Creative Commons Attribution (CC BY 4.0) licence. Anyone may reproduce, distribute, translate and create derivative works of this article (for both commercial and noncommercial purposes), subject to full attribution to the original publication and authors. The full terms of this licence may be seen at http://creativecommons.org/licences/by/4.0/legalcode

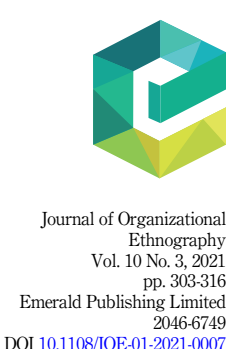

DOI 10.1108/JOE-01-2021-0007 
JOE
10,3

304

lived experiences in order to understand creating ideas as social and cultural experience (Ellis, 2004). One of us suggested that we look into the concept of "etiology," or reflection on how things become as they are, in making sense of how ideas (fail to) catch on. This was a provocation (De Bono, 1992), or "a disturbance in our thinking process for opening up a new territory" (Provost and Langley, 1998, p. 33), which was met with a mix of excitement and suspicion. It led us to turn the noun into a verb, "etiologizing," to engage in a dialogue about what it could mean and to learn about creating ideas together in conditions of remote online work.

In this paper, we theorize our collaborative autoethnography with the concept of "idea work," which refers to activities concerned with generating, selecting, realizing, nurturing, sharing, materializing, pitching and communicating ideas (Carlsen et al., 2012). Idea work is a way to question individualistically heroic tales of invention. For Carlsen et al. (2012), idea work is based on creativity inherent in collective processes, and it helps make sense of how creativity occurs in collaborative efforts. Ideas can be thought of as composite and intertextual; a weave of interconnections between related and similar ideas or between parts and wholes (Coldevin et al., 2019). Connections flourish in dialogical encounters that are open-ended and live on the boundaries of individuals (cf. Bakhtin, 1981). Our online collaboration is an example of how dialogical encounters can play out. This paper focuses on a specific part of the idea work experience; "prep work" that refers to its initial stages (Carlsen et al., 2012). We use the process of crafting this paper as its empirical material.

Specifically, we develop the concept of idea work so that it enables us to address emotions and identities in creating ideas together. Carlsen et al. (2012) reserve the term for "work with ideas that require organizational attention and interaction over time, where one needs to consider alternatives, and where major changes or new deliverables are at stake" (p. 38). Based on our collaborative autoethnography, we argue that idea work is related not only to emotions but to our identities too. We are intrigued by the way emotions and identities (Lawrence and Phillips, 2019) play into idea work, lead us to discover something that we did not set out to find and help learn about ourselves as creators, or killers, of ideas. Etiologizing, rather than etiology, became an idea that we developed together. It helped us create a "shelter" or safe space for getting our dialogue going, and it became a "crutch" to lean on. Eventually we sought to abandon etiologizing as a crutch and to nurture everything that it had enabled us to create together. In this paper, we recount our remote collaborative autoethnography and theorize the notions of shelter and crutch in idea work.

\section{Let's get together}

Autoethnography is about studying ourselves in social and cultural context. It helps generate meaningful and accessible research that is grounded in personal experience (Ellis and Bochner, 2000). COVID-19 and its effects on academics have generated a wealth of new autoethnographic work. The unusual circumstances of our lives have prompted reflections on time (Bolander and Smith, 2020), knowing and (self-)expression (Pruulmann-Vengerfeldt, 2020) and effects of technologies on our experiences (Liedtke Thorndahl and Nørgaard Frandsen, 2020). We believe that autoethnography helps to capture those aspects of creating ideas together that would otherwise remain hidden (cf. Doloriert and Sambrook, 2012); it enables us to highlight the collective work that is necessary for creating the conditions for insights and ideas to occur and develop (Locke et al., 2008). Too often this work remains hidden.

We engaged in collaborative autoethnography, which is about sharing, discussing and theorizing experiences, insights and ideas together (Geist-Martin et al., 2010; Chang et al., 2012). Collaborative autoethnography enabled us to "pool our lived experiences" (Hernandez et al., 2017), to establish a dialogue on their complex and relational nature (Bissett et al., 2018), to shift from individual to collective agency and multivocality and to offer 
"personally engaging, nonexploitative, accessible research" (Lapadat, 2017, p. 589). The first author is working on her $\mathrm{PhD}$ dissertation and figuring out her position in academia and in life. The second author is her supervisor and an experienced professor. The third author was the previous supervisor, before becoming professor in a university in another country. The first author reflects: "Our relationship is now closer. I learn from the others; I see my coauthors beyond their professional roles, as people like me who get inspired by ideas." The second author says that he tries to engage in every new research initiative as if it were the first. He feels that he needs to overcome the burden of experience to be able to think clearly and write engagingly. The third author confesses a love of ideas but admits to impatience: once an idea becomes familiar, it seems a good time for her to move on to exploring something new. Our collaborative autoethnography offered a mirror through which we could look at our journey of exploration - and to learn more of ideas and of ourselves.

Collaborative autoethnography includes joint reflection and critique of personal stories (Geist-Martin et al., 2010). In keeping with this method of inquiry, we first engaged in a dialogue where each of us crafted short texts separately, taking turns, and followed up on others' thoughts and texts. "Etiology" was its point of departure. Between episodes of individual writing and sending emails, we discussed in Skype meetings what we had crafted and what we may write next. The quotes below are snippets from this first phase of our research. It is not relevant, we argue, who originally said what. We developed a common narrative. This was done in the second phase, where we engaged in joint analysis of our original texts. We interpreted what they mean and how they (fail to) relate to each other. Our research process is outlined in Table 1.

Etiology as a provocation (De Bono, 1992) and disturbance (Provost and Langley, 1998) led us to engage in creating ideas. In our dialogue and analysis, we began to talk about ideas as "shelters" and "crutches." We discussed how shelters are created out of concepts and ideas to find creativity, excitement and comfort in our ambiguous and precarious academic lives. In safe and gentle modes of collaboration in the shelter, we could question ourselves, share and explore the world together. We noticed that over time our shelter turned into a crutch that we could lean on in developing our thinking and writing. We discussed how and why we had begun to rely on our idea.

While the quotes below are from our original dialogue, the narrative and commentary were created in the analysis phase. We realized that feelings and emotions, and dealing with them together, were crucial for creating ideas. Courage was needed to share one's emotions, and this could be done in the shelter. We came to think of the shelter as a shared, safe social and mental space. We also noticed that our identities as (aspiring and more established) academics were at play when we dealt with our emotions together. We used imaginative ways of moving forward when the dialogue seemed to stall. This includes short play writing: a bat (evoked by the COVID-19 pandemic) played a part in it, providing a nonhuman, even wild, imaginary sparring partner for our reflections. We could work on our identities together in our dialogue. Such joint identity work is characteristic of universities today where our work is meticulously controlled and our identities are subject to tensions and struggles (Nordbäck et al., 2021).

As such, we slid into theorizing our dialogue and analysis, which is the final phase of collaborative autoethnography (Geist-Martin et al., 2010). We discussed how to theorize our narrative in order to move beyond our personal experiences and joint reflections and to say something meaningful about idea work online. We engaged in theorizing our dialogue by building on reflections of emotions and identities and by seeking to understand how emotions and identities play into idea work as, and in, shelters and crutches (cf. Carlsen et al., 2012; Lawrence and Phillips, 2019). We conceive identities as our subjectively but socially construed understandings of who we were, are and desire to become (Brown, 2015). Identities are formed in interactions with others, and working on identities involves emotions and emotional talk (Winkler, 2018). Emotions are discursive resources that can be mobilized in 
JOE
10,3

306
Time Activities

January-April, 2020

(1) Email and phone discussions on creating ideas and etiology by Authors 1 and 3; Author 2 invited to join

Joint discussion 1 on Skype (ca. 1.5 h)

(1) Creating ideas and the concept of etiology

(2) Engaging in collaborative autoethnography

(3) Writing texts based on lived experiences

(1) Three rounds of writing texts (200-400 words) where Author 3 starts each round, followed by Author 1 and Author 2; emails, intervals 1-7 days

May 15

Joint discussion 2 on Skype (ca. 1 h)

(1) Reflecting on first round (i.e. on three texts by each author); identifying common themes and differences; agreeing on direction of texts in next round

May-June

(1) Three rounds of writing texts (200-400 words) where Author 3 starts each round, followed by Author 1 and Author 2; emails, intervals 1-7 days

June 9

Joint discussion 3 on Skype (ca 1 h)

(1) Reflecting on second round (i.e. on three texts by each author); identifying common themes and differences; agreeing on direction of texts in next round

June-August

(1) Three rounds of writing texts (200-400 words) where Author 3 starts each round, followed by Author 1 and Author 2; emails, intervals 1-7 days

August 11

Joint discussion 4 on Skype (ca. 1 h)

(1) Reflecting on third round (i.e. on three texts by each author); identifying common themes and differences

(2) Analyzing all three rounds: commenting on how own and others' texts are related

(3) Agreeing on next steps

August-September

(1) Iterating: each author reads all texts separately and develops suggestions for a joint narrative

Joint discussion 5 on Skype (ca. 1 h)

(1) Analyzing all three rounds continues

(2) Discussing a joint narrative and theorizing it

(1) Iterating: Author 3 highlights interesting quotes; Author 1 picks quotes for initial narrative draft; Author 2 writes interpretations of selected quotes; Author 1 offers more specific ideas for theorizing

September 30

Joint discussion 6 on Skype (ca. 1 h)

(1) Theorizing continues

(2) Agreeing on how to "write up" paper

(1) Iterating: Author 2 writes paper; Authors 1 and 3 comment; all authors continue analysis (of texts) and theorizing; comments on each other's analysis and theorizing; writing proceeds
September, 2020January, 2021
Our remote collaborative autoethnography and for identity work (Coupland et al., 2008). Talk about emotions offered us ways to navigate discrepancies between our "ideal selves" (here, as academics creating ideas) and our experiences of idea work online (Ahuja et al., 2019).

We also considered how time, space and power relations condition our idea work. We began to write to each other in exceptional circumstances where we worked remotely as the COVID-19 
pandemic spread across the world. We were sensitive not only to our different and often unequal chances to work at home but also to opportunities to do something together that we would not do in "normal" circumstances. Time and place go together, and if we assume that place is a social construct (Grey and O'Toole, 2020), the temporal, spatial and social are connected in our dialogue. Online spaces change the displaying and sharing of emotions. Shame (for not pulling one's weight) and fear (for letting others down) are among the many emotions that often characterize research collaboration. There is also joy and excitement when collaboration becomes meaningful. Disembodiment in online spaces allows us to regulate what we share about ourselves and to express hoped for aspects of our identities, which we may hesitate to share face to face. Disembodiment shifts the emphasis in expressing identities online from physical material cues to what is shared in texts and (moving) images. Still, we cannot escape how our academic lives are sustained by power relations concerning doctoral researchers and their supervisors. We entered the collaboration from different vantage points. . We revisit ideas as shelters and crutches in the discussion, where they help us theorize emotions, identities, online spaces and power relations in idea work. Next, we offer our narrative in the form of a play in three acts. It is written in present tense. It consists of a selection of our original texts, which we have assembled into a narrative with a structure, plot and commentary.

\section{First act: idea as shelter}

The first act sets the scene. Engaging with the concept of etiology we work with our emotions. We wonder, immerse ourselves in the collaboration and dare to imagine. We begin to imagine what a shelter for creating ideas together can mean.

\section{Etiology?}

We wonder and encounter something new, unexpected and mysterious. We activate our sense of drama and share our thoughts with each other.

Here is collaborative creativity staring me right in the face: how might I come to terms with it in these virus-infectious, remote working times? Never a better time to immerse in etiology.

In these strange times when we are all locked down and working at home this is an excellent idea. Many of us are struggling to reach out to others and get social again. This is the right time to do something like this because many phenomena that usually remain hidden are now wide open.

We evaluate the potential of etiology from the point of elegance, attractiveness, arousal, and interest. We etiologize and make it our aesthetic home. Maybe the concept is a shelter for creativity against the threats of life by a viral disease the etiology of which is contested.

It's interesting that we need a shelter for creativity (in a form of a concept). In that sense a concept is an empty space, that we can fill in with our daily worries, struggles and aspirations, like actors make characters unique and familiar by imbuing them with their own lived experiences.

In the shelter we try to find safety from knowing that somewhere there is an "ultimate truth," that not everything is social and debatable. However, sometimes this fantasmic quest for meaning turns into a disease.

We have come close and intimate - we do not care where the study of etiology comes from: medical/ natural sciences. It is as if we took, or hijacked, the concept and made it our own, not minding that what appears strictly defined a rational approach to study, we have made a matter of our aesthetics.

Etiologizing speaks to us as it embodies the shaking of many traditional boundaries: of identity, discourse, and action. 
JOE
10,3

This situation is illustrative of our life anxieties, where we worry that someone else may invent the world and our place in it for us. But how can we be scared if there is no "ultimate truth" about what comprises us in reality? I agree that we etiologize concepts to make them better fit the world we live in.

\section{Finding oneself in the voices of others} that imaginative ideas bring excitement, opportunity and a sense of purpose to our joint work. But there is always doubt, too, in idea work.

Society teaches us to acquire things, ideas, relationships infused with meanings which keep us in captivity. Freedom is not when we have nothing to lose. Instead, it's realizing the constructed nature of reality and our responsibility in creating it.

Do your research. But it is not your "own." That's why sharing like this is so fabulous, even if I am getting a bit impatient again;-) If everyone gets to come up with whatever they find useful, well, what happens to the Academic Police?

Etiologizing in online spaces is intriguing. All this weird stuff that is going on in social media and elsewhere makes it ever harder to distinguish between what is "true" and what is not. Representation and meanings. Until the disease makes you sick, really.

If instead of focusing on representations and meanings we think of freedom, as ability to reflect, as our experiment shows, in remote format may not necessarily be a limitation, if not exactly an enabler.

This is slippery. But I'm willing to try. After all, playing around with ideas needs a bit of friction. In order to move forward, I must get rid of some of my excess baggage. Can I change my thinking so that we can move forward? Must I do that? Or can we work with different understandings of ideas (and their origins and how they develop) that may complement each other?

I think one way to answer the question of what makes the concept of etiology relatable as an idea, is to try to understand what drives us to write these notes. Maybe this reflection that helps me to continue is a way of telling a myth, as we all pick up a feeling and then put it in a context, give some explanation to it, which adds layers to our stories. Is it possible instead to experiment and be led by whatever happens to us? If not, why?

Your texts inspired me to enjoy writing, making it easier and more pleasant. It resulted in less questions and more openness, but most of all, boosts of energy. I wonder whether me asking questions is an attempt to refocus attention away from myself?

How amazing it would be to let oneself free from the limitations of research having to be a certain way. How often should we engage in liberating brain-dumping to feel that we are alive? But is not it a fantasy that liberated from norms and concepts I feel happier? I suspect that these aesthetically satisfying and relatable fantasies keep us etiologizing.

\section{Momentum of insights}

We feel startled but engage in a search for meaning and purpose together. We imagine progress in our idea work and find that the shelter works for us.

In the best of moments, you lose sight of the focal concept or idea, and it is everything around it that matters most. This is what happened to me on this Monday morning. In due course, I return to the concept. With your help. Finding meaning is not exactly a fool's game but sometimes it feels like fighting windmills. Following in the footsteps of Don Quixote. Finding shelter with a concept is at the same time emotional labor and analytical inquiry. It is mundane magic. Like Baron von Munchausen pulling himself up from a mire by his own hair. Laying bare how difficult (and rewarding) creating ideas is when you do it together. 
Not sure where I am going with this or where I am coming from. I am stopping for the moment, at the theater bus stop that says "Etiology" in big red letters as the show playing tonight. My name is among the cast. I am keen to think of what my lines are. The thing is, it is possible to only look at part of the content at a time, otherwise its etiology takes you over. Then there is no return.

Here's another play with words. Flash insights versus Waiting for Godot. Insights are - and perhaps must be -flashes of some sort where you suddenly understand something better. However, there will always be dullness and boredom and waiting for those flashes that may never come.

This is what makes our collaboration so enjoyable. Not knowing if there is anything to win, and still doing it. It is better to leave than to arrive. "Why would it matter where we drop out?" A lovely question. No-one will notice if we do not arrive. But we have left, for sure, and that is what matters.

We do not leave but return to the same concepts, as they evolve and get new meanings while we "left" them unattended. Maybe leaving, after all, is a necessary step in order to come back, as just another element of etiologizing?

Sharing provides opportunities for learning about others and ourselves; getting experienced in navigating social scripts. There is no one authentic self to be discovered, instead we continuously construct our understanding of self.

We each express our emotions differently but can now engage in mutual emotion work. Through reflection and dialogue, we learn from each other. When the reciprocity of a safe space, the "shelter," is established, we can take a closer look at our identities as academics and as creators of ideas.

\section{Second act: learning (about) ourselves}

The second act introduces the three authors as actors. We construct our ways of being in the world as creative people in dialogue with others. We work on our identities and (re)discover the more controversial elements in idea work.

\section{The one who asks questions}

The first author acknowledges doubt and friction, not as noise to be avoided, but as levers with which to question the taken-for-granted, to enhance imagination and to help ideas to flourish.

To me etiology speaks about how our own thoughts develop over time influenced by others and our own reflections. I wonder if it is even possible to say that anything in my thinking is completely mine?

I see working with the idea of etiology as a complicated puzzle and the collective process of making pieces come together... When we engage with it, we engage with something within us that we fantasize this concept resembles for us: familiarity, challenge or confusion, complexity, connectivity in co-creation. Etiology sounds like an interesting alley! I see it as something airy, a bit distant from everyday life, perplexing, obscure.

When you contemplate on changing something in your attitude, to me it sounds like making a decision and being in control. I wonder: how can you be sure that your new thinking will be more helpful? Do you know what you are aiming at? Why is it so important? How much of responsibility and control over that do you really have?

Our expectations are mostly our thoughts of others' expectations of us, which in many cases are binding us. Reflecting that idea creation is too routine-like to move on, is in fact a step forward? Thinking about time and putting it into perspective, is another step. Still deciding to move on and to pull oneself out of a rut is the final sprint. Even when we lack reflection or ramble on unrelated topics, we are still here.
Idea work online 
The second author embraces creating ideas through playfulness and humor with the aim of building social ties, relaxing constraints in thinking and encouraging original combinations of things we may not ordinarily think about.

If there is no flash, you make it happen. Or you make a mockery out of it. Even if you risk your reputation. That is why I've always sided with Fools and Jesters. At the end of the day, arriving is not that crucial for me. Enjoying the playing is more important than winning. With these words, I am back to the beginning. I forgot about etiologizing. Again!

My thinking and writing are related to you and your writing. I guess I became an academic because I like to question things. And people. This includes me and my own thoughts. I find that my thinking develops, at least for a fleeting moment, then the questioning starts again. The point I want to make is that I cannot do this alone. I need you.

Have we learned something about ourselves? I know I have. I'm learning to etiologize etiology, and to look at myself reacting and acting in doing so. You are nudging me to sort out my messes. When Iam not forced but gently guided, I feel creative. And a bit of joint self-reflection is always a good idea.

So etiologizing merges with the etiologizer. It becomes yet another building block in my identity work. There is nothing outside the discourse and the act. The play goes on, even if we find no part in it. It arouses emotions and feelings. It runs around in circles, but it also breaks free and offers our imagination new things to invent.

\section{The holder of the concept}

The third author uses audacity and initiates actions to open up, to mobilize against established ways of thinking and acting and to realize ideas that are original and valuable.

I have turned to etiology before, to explore ways in which rigidity might be beneficial for stubborn biotech companies not willing to admit failure and keep developing a sepsis treatment (that did not work in the end). But! These companies develop a lot of valuable knowledge in the process of etiologizing.

What strikes me is that we relate to this concept completely differently from its formal, somewhat rigid and hygienic definition - mapping the causes of diseases over time, all done in a sort of standoffishly neutral way. We have taken the liberty of bringing into the discussion our feelings and conceptual likes and dislikes.

Etiology links eternity over time. But who would want to live that long, with something so BORING as etiology?! Not only fools make things up. Creative people do, too. The art is to make something cute, zany or interesting. Or, invent your own categorizing - like etiology. It is such a sky highsounding concept that a lot of creativity can be hidden into it.

This writing thing has become a sort of diary. I cannot believe I am spilling my inners here - well, you did ask to show more of myself. [Read: blame yourself. No, read: thank you for asking.] What if you are yourself, authentic, but you are actually a horrible person? Would it not be better to hide? Or, if you reveal a lot about yourself, you become human ... That can be dangerous. Down with the pedestals! Push the statues down! Break them! Down down down.

We share more about ourselves as academics and as creative people. Through reflection and dialogue, we learn to trust each other enough to engage in shared emotion and identity work. We no longer need a shelter, but something more instrumental; a crutch.

\section{Third act: idea as crutch}

In the third act, the idea takes center stage. We trace what happens to it in its journey between people, how it stabilizes as a shelter and how it becomes a crutch and something to be questioned again. 
Etiology. Welcome, Good Friend, let us go for another adventure for discovery. I am glad to have found a new use for a concept that feels like putting in an old, but oddly comfortable, shoe. Even if I do not know of all the walks the shoe has been taking, I am ready for a long walk in the woods, even hopping on one foot.

I suggested that we take etiology as a starting point, as an initial focus around which we can start a trialogue. Would etiology work in making sense of how we can be creative together in conditions of remote work?

Is the concept of etiology helpful to a study of collaborative creativity? It may not be, yet it provokes something. Maybe what Karl Weick said is true here, too: it does not matter what map you have as long as you have some map, when lost? Concepts are meaningless until we give them meaning.

When we think we like something it's not the idea that we like, but a fantasy we create in our heads. I guess liking in this context does not mean being in favor of, but rather continuity of engagement. We all have different myths connected to the concept of etiology ("an old, but oddly comfortable, shoe," "concept from natural sciences," "causation" etc.).

Touché! I am questioning this particular metaphor, idea or concept (for studying what ideas do) because I have for so long been confident that there are better ones, those I have used before, like "translation," those that are nice and safe for me.

\section{Letting the idea lead}

The idea is discussed and stabilized. A more explorative part of the prep work begins, and we bravely generate questions and answers. We wonder about ourselves as creative people but arrive at something meaningful.

Maybe it's important how we engage with ideas, interpret them, consider what makes us like or dislike them. How do ideas become relatable? How us relating (or not) to certain ideas develops them further? Maybe it's not about allowing time, but a space for an idea in one's mind. Not being rigid.

The reason I think etiology has potential is that it reminds that people may not be the causal agents of collaborative creativity but ideas themselves may have more power over us than we allow. So, it may be wrong to only focus on what people do, not what ideas do. Look at us! Seduced by an idea we do not even understand!

Maybe ideas manipulate us? Hand on my heart, I am manipulated by these competing meanings for etiology, by sociological and linguistic understandings of how ideas travel and are translated in their travels. "Travel," of course, is another metaphor I'm using. Now I am being vague. One way or another, I am led by the social and the interactional.

Agency? Ideas have agency, people much less than they think, Irepeat. We use our agency to express ourselves in particular concepts. Maybe etiology allows us to show ourselves in a role of an etiologist thus revealing something that otherwise would remain hidden? Our theater is conceptual. Which concept would you like to play tonight as your role?

Etiologizing has become an umbrella term for what we are doing here rather than what some etiologists par excellence might be doing - such as mapping the COVID-19. So, to coin a term - to etiologize is to aesthetically explore the world with concepts that trigger emotions. Why emotions, life narratives, and aesthetics? Because at the end of a research day, that is what matters. It intellectually challenges us. Wakes us up.

\section{Using the idea to make sense of our collaboration}

The idea gives us a safe space in an unsettling time and supports us in reflecting on our identities. After working on our emotions and identities, we can confront and evaluate the idea. It crystallizes and turns into a crutch that we can lean on. 
JOE

10,3
I realize that I sound like a control freak . . but I guess I am looking for some sort of a frame within which we can be creative together.

To label is to understand. Maybe. And frankly, in academia, it is not really so often about understanding the issues as it is representing them in some conceptual framing - Etiology!!!, guilty as charged. Yet concepts sometimes offer new perspectives when trying to examine something through a different looking glass.

Do concepts have to be brought to life? Are they not devices to make sense of the world? The world is constantly changing, so our concepts must be contested and developed, too.

We've established creating meanings as one element of etiology. Politicking is an external manifestation of identity etiologizing, as we cannot etiologize the world without etiologizing ourselves ... In this etiology quest we attach to concepts and then suffer if we cannot keep them. What if we accept the not knowing, make peace with being foolish, vulnerable, threatened creatures, instead of powerful, controlling, super-intelligent humans? Can we learn to engage with concepts, "try them on" like roles and move on?

It seems like we are on a hunt for some implicit indication of our etiology play being over. And it needs to be a certain kind of ending. What do we lose if it does not match our imagined desired format? Do we want to grasp something just enough to feel free moving on? Or maybe to finish is to end the restlessness of bearing with something too routine-like? Most importantly, why are we responsible for delivering this ending?

Isn't etiologizing eternal and bigger than us? Aren't we then thinking too much of ourselves by assuming we can grasp it? Why would it matter where we drop off, if our rambles are only small pieces in the puzzle and arrival is only subjectively meaningful.

We have created a crutch in the idea of etiologizing, and now we lean on it. How can we stop leaning?

\section{Discussion}

After presenting our remote collaborative autoethnography in the form of a play, we now theorize idea work in online collaboration. We develop the notions of "shelter" and "crutch" to make sense of the complexity of creating ideas together; to consider how idea work, emotions and identities are entangled; and to discuss how time, space and power relations condition it.

First, our collaborative autoethnography shows what shelters and crutches can be and how they can play into idea work. While "etiology" as a provocation (De Bono, 1992) or a disturbance (Provost and Langley, 1998) led us to engage in creating ideas together, the idea of turning etiology into etiologizing became a shelter where we could get to know each other and each other's thinking and emotions, feel safe and be creative. We began our collaboration with the expectation that we must be efficient in performing idea work and to make our idea interesting and useful for others. Our dialogue began to be meaningful only when we managed to become more appreciative of our different insights and their unfinished nature. The unpredictability of the outcome of the search for ideas became a prerequisite for embarking upon and continuing the journey. This needed to find a space - a shelter - where the pain in creating ideas together (ambiguous expectations and pressure) could turn into pleasure (joy of understanding and discovery). The conditions of online remote work during the COVID-19 lockdown pushed us to see the crucial importance of creating this space together. Our shelter helped us to cultivate doubt as a central and generative feature of creating ideas, and it enabled us to value and engage surprises, hunches and disorder in our dialogue (cf. Locke et al., 2008).

As Bakhtin (1981) noted, every idea is linked to other ideas leading to it, underpinning it and following from it. Connections between ideas do not adhere to minds of individuals but 
flourish in the public sphere of texts and other artifacts (Coldevin et al., 2019). They are nurtured in dialogical encounters (Bakhtin, 1981) such as those enabled by our shelter. Ideas are rarely singular or discrete, countable and independent entities that are developed and evaluated irrespective of context; we must be attentive to activities through which ideas are created as well as to the context of their creation (Coldevin et al., 2019). It is the importance of this context as a shared space that we have highlighted in this paper. We engaged in legitimating our imaginings in the shelter where ideas of what to do were connected to what is worth doing. This legitimating imagining (Coldevin et al., 2019) related both to our personal aspirations to do something meaningful and to social expectations of collectivity and value. However, our shelter became a crutch that we could lean on, and it hampered developing our thinking and writing further. We found how difficult it was to get rid of the crutch and to crystallize and finalize the idea that we thought we had developed. In preparing ideas for further development (Carlsen et al., 2012), then, it is essential to let go of some of the original commitments and to move on together.

Second, our collaborative autoethnography elucidates how idea work (Carlsen et al., 2012) is infused with emotions and identity work. The shelter helped us deal with our emotions together and to reflect on our identities as academics, and it became a crutch that we could lean on. The crucial point here is that emotions are relational. We came to understand displaying emotions as a collective and at times even a coordinated, accomplishment (Boje, 1995). In our remote collaborative autoethnography, it was crucial that we displayed our emotions so that we could turn them into a creative force. Emotions played into our identity work as we (re)constructed our identities through others. We "talked our way into" identities and sought to establish who we are in the eyes (or voices) of our collaborators (Lawrence and Phillips, 2019). We did this in declarations, arguments, questions and answers, conversations and dialogue. The ways in which we shaped our emotions shaped our senses of self. It was difficult and confusing to give (new) meanings to something we labored to understand. A way forward was to look at ourselves and at each other, at our feelings and thoughts; at everything around the concept we were trying to grasp. In the shelter, the self was reflected in others' eyes and voices. The shared space conditioned the forms and outcomes of our idea creation through our emotions and identities.

Engaging in dialogue in a remote collaborative autoethnography enabled us to get close and to keep our distance and to alter between closeness and distance. As cues about positioning of one's (academic) identity online were more subtle compared to offline communication, our ability to enforce "feeling rules" on the dialogue decreased, and we could extend the range of emotions and carve out a space for shared identity work (Lawrence and Phillips, 2019). Our study thus testifies for the importance of creating spaces (social, mental and symbolic) to be filled with meanings. We carved out a shared space, or shelter, with our engagement with first etiology and then etiologizing. A joint practice of nurturing this space emerged, and it allowed us to continue our collaborative autoethnography and idea work. It helped us deal with the obstacles in only being able to spur each other on in short moments while our contemplation did not stop when we stopped writing to each other.

The shelter as a space and as an emerging shared practice helped us to engage with our emotions and identities. We found ourselves switching between working on an idea to working on our emotions and identities. We could explore potential limitations of our practice, where the interplay of different kinds of work could lead to impatience, boredom and unwillingness to continue. We found that identity work needed to be done in order to continue the idea work, and we learned that emotions needed to be displayed to continue working in difficult moments as well as in moments of excitement and joy. Our work on ideas, emotions and identities thus fueled each other.

Creating a shelter and letting it develop into a crutch helped us to cultivate and preserve experiences of wonder (Carlsen and Sandelands, 2013) and generative doubt (Locke et al., 
JOE
10,3

314

2008) that are crucial for idea work to flourish. We could foster movement - or nonjudgmental "thinking that carries the concept forward to produce new connections" (Provost and Langley, 1998, p. 33) - and explore the relation between shelter and crutch. Movement toward the crutch helped us stay receptive to uncertainty and not knowing (Page, 2017) and to cherish hunches, which may occur in idea work. Instead of rushing after "flashes of insights" and coming up with quick conclusions, through our "vulnerable writing" (Page, 2017, p. 1), we managed to do our prep work and to construct the shared space that prepared the ground for insights (Carlsen et al., 2012). We continued our journey until we realized that the crutch became redundant. This realization was emotional, as the crutch could no longer support us in handling our restlessness (Carlsen and Sandelands, 2013).

Third, and finally, our study shows how power relations play into creating ideas in conditions of remote collaborative autoethnography. Here, we build on an understanding of power that grew out of Michel Foucault's $(1977,1984)$ work. Foucault conceptualized social actors as controlled and disciplined by practices and discourses, which construct subject positions and identities. In this view, power is in relations. The dynamics of our dialogue reflect our relative (academic) positions, assumptions, interests and identities, time and place orientations and emotional attachments. Jointly developing a shelter was to create a shared space that was not only productive but allowed the formation of trust so that idea creators from different organizational positions and with different backgrounds could experience conditions of work that were safe enough for them to be creative and to share their insights.

In taking distance to our differing positions - and acknowledging the power relations that condition our collaboration - we created shared emotional intimacy with the idea we were developing. We began to mindfully monitor, and signal to each other, occurrences of doubt, frustration and arrival at decisive questions and answers. Sometimes the process was stressful as we had to encourage emotions that would support appropriate distance and suppress feelings that could disturb the intimacy we managed to construct through our online dialogue. The shelter we talk about was not only a shared social, mental and symbolic space but a way for us to gently test the possibilities and limits of our collaboration, which is conditioned by asymmetric power relations. For identity work, this meant that we worked on multiple (sometimes conflicting) selves: the one who stays open and alert to insights from others, the one who is actively exploring and the one who resists to be led by the idea (Sandelands and Carlsen, 2013). We collectively negotiated our identities by weaving emotions into alternative identities, expressing empathy and attending to each other's feelings and reflecting on how we can collaborate meaningfully. Overall, we found that creating ideas is a profoundly relational process embedded in power relations.

In the Foucauldian view, acts of resistance are an inherent part of power relations. One way to understand this is that resistance is related to how we come to know and challenge the ways in which our identities are constituted in hegemonic discourses (Holmer-Nadesan, 1996). We experienced this in our collaborative autoethnography as we negotiated what the shelter and crutch mean for us. We engaged in dialogical constitutive work of connecting, disconnecting and assembling constellations of ideas that crystallized in imagining the idea of etiologizing (Coldevin et al., 2019). Resistance took the form of questioning our joint initiative and what it meant for us. We suggest that power as "co-optative" (dialogically situated in building connections) works not only in constellations of ideas in some larger "field of ideas" in the organization and beyond (Coldevin et al., 2019), but also in online idea work among a group of academics. As Bakhtin (1981, p. 293) reminds us, all work on ideas is "half someone else's." The notions of shelter and crutch help us appreciate its shared complexity and incompleteness as well as the importance of being aware of power relations in building shared spaces for idea work. 


\section{References}

Ahuja, S., Heizmann, H. and Clegg, S. (2019), "Emotions and identity work: emotions as discursive resources in the constitution of junior professionals' identities”, Human Relations, Vol. 72 No. 5 , pp. 988-1009.

Bakhtin, M.M. (1981), The Dialogic Imagination: Four Essays, University of Texas Press, Austin, TX.

Bissett, N., Saunders, S. and Bouten Pinto, C. (2018), "Collaborative autoethnography: enhancing reflexive communication processes", in Vine, T., Clark, J., Richards, S. and Weir, D. (Eds), Ethnographic Research and Analysis: Anxiety, Identity and Self, Palgrave Macmillan, London, online pp. 253-272.

Boje, D.M. (1995), "Stories of the storytelling organization: a postmodern analysis of Disney as 'Tamara-Land”, Academy of Management Journal, Vol. 38 No. 4, pp. 997-1035.

Bolander, B. and Smith, P. (2020), "Time across the lines: collaborative wonderings under COVID-19", Qualitative Inquiry, Vol. 27 No. 7, pp. 835-843.

Brown, A.D. (2015), "Identities and identity work in organizations", International Journal of Management Reviews, Vol. 17 No. 1, pp. 20-40.

Carlsen, A. and Sandelands, L. (2013), "Living ideas at work", in Pitsis, T.S. and Simpson, A. (Eds), Handbook of Organizational and Managerial Innovation, Edward Elgar, Cheltenham.

Carlsen, A., Clegg, S. and Gjersvik, R. (2012), Idea Work, Aschehoug, Oslo.

Chang, H., Ngunjiri, F.W. and Hernandez, K.-A. (2012), Collaborative Autoethnography, Routledge, New York.

Coldevin, G.H., Carlsen, A., Clegg, S., Antonacopoulou, E. and Pitsis, T. (2019), "Organizational creativity as idea work: intertextual placing and legitimating imaginings in media development and oil exploration", Human Relations, Vol. 72 No. 8, pp. 1369-1397.

Coupland, C., Brown, A.D., Daniels, K. and Humphreys, M. (2008), "Saying it with feeling: analysing speakable emotions", Human Relations, Vol. 61 No. 3, pp. 327-353.

De Bono, E. (1992), Sur/petition, Harper Collins, London.

Doloriert, C. and Sambrook, S. (2012), “Organisational autoethnography”, Journal of Organizational Ethnography, Vol. 1 No. 1, pp. 83-95.

Ellis, C. (2004), The Ethnographic I: A Methodological Novel about Autoethnography, AltaMira Press, Walnut Creek, CA.

Ellis, C. and Bochner, A.P. (2000), "Autoethnography, personal narrative, reflexivity", in Denzin, N.K. and Lincoln, Y.S. (Eds), Handbook of Qualitative Research, Sage, Thousand Oaks, CA, pp. 733-768.

Foucault, M. (1977), Discipline and Punish: The Birth of the Prison, Penguin, Harmondsworth.

Foucault, M. (1984), The History of Sexuality: An Introduction, Penguin, Harmondsworth.

Geist-Martin, P., Gates, L., Wiering, L., Kirby, E., Houston, R., Lilly, A. and Moreno, J. (2010), "Exemplifying collaborative autoethnographic practice via shared stories of mothering", Journal of Research Practice, Vol. 6 No. 1, article M8.

Grey, G. and O’Toole, M. (2020), "The placing of identity and the identification of place: 'Place-identity' in community lifeboating", Journal of Management Inquiry, Vol. 29 No. 2, pp. 206-219.

Hernandez, K.-A., Chang, H. and Ngunjiri, F.W. (2017), "Collaborative autoethnography as multivocal, relational and democratic research: opportunities, challenges and aspirations", Autobiography Studies, Vol. 32 No. 2, pp. 251-254.

Holmer-Nadesan, M. (1996), "Organizational identity and space of action", Organization Studies, Vol. 17 No. 1, pp. 49-81.

Kiriakos, C.M. and Tienari, J. (2018), “Academic writing as love”, Management Learning, Vol. 49 No. 3, pp. 263-277. 
Lapadat, J.C. (2017), "Ethics in autoethnography and collaborative autoethnography", Qualitative Inquiry, Vol. 23 No. 8, pp. 589-603.

Lawrence, T.B. and Phillips, N. (2019), Constructing Organizational Life: How Social-Symbolic Work Shapes Selves, Organizations, and Institutions, Oxford University Press, Oxford.

Liedtke Thorndahl, K. and Nørgaard Frandsen, L. (2020), "Logged in while locked down: exploring the influence of digital technologies in the time of corona", Qualitative Inquiry, Vol. 27 No. 7, pp. 870-877.

Locke, K., Golden-Biddle, K. and Feldman, M.S. (2008), "Making doubt generative: rethinking the role of doubt in the research process", Organization Science, Vol. 19 No. 6, pp. 907-918.

Nordbäck, E., Hakonen, M. and Tienari, J. (2021), "Academic identities and a sense of place: a collaborative autoethnography in the Neoliberal University", Management Learning, 13505076211006543.

Page, T. (2017), "Vulnerable writing as a feminist methodological practice”, Feminist Review, Vol. 115 No. 1, pp. 13-29.

Provost, L.P. and Langley, G.J. (1998), "The importance of concepts in creativity and improvement", Quality Progress, No. March, pp. 31-38.

Pruulmann-Vengerfeldt, P. (2020), "The ways of knowing the pandemic with the help of prompted autoethnography", Qualitative Inquiry, Vol. 27 No. 7, pp. 812-819.

Sandelands, L.E. and Carlsen, A. (2013), "The romance of wonder in organization studies", Journal of Management, Spirituality and Religion, Vol. 10 No. 4, pp. 358-379.

Winkler, I. (2018), "Identity work and emotions: a review", International Journal of Management Reviews, Vol. 20 No. 1, pp. 120-133.

\section{Corresponding author}

Anna Dziuba can be contacted at: anna.dziuba@hanken.fi

For instructions on how to order reprints of this article, please visit our website:

www.emeraldgrouppublishing.com/licensing/reprints.htm

Or contact us for further details: permissions@emeraldinsight.com 